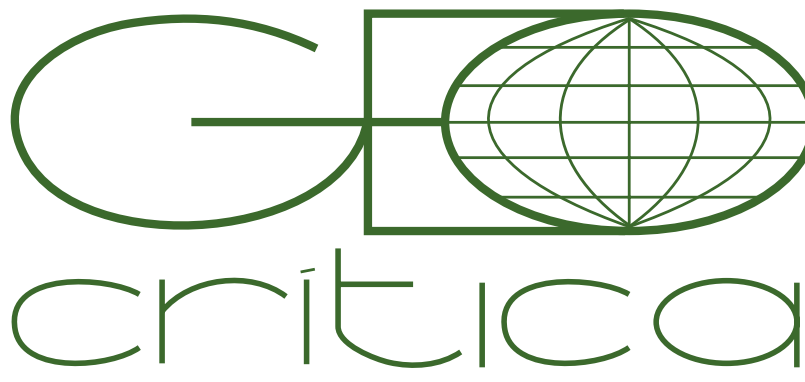

\section{Scripta Nova}

Revista Electrónica de Geografía y Ciencias Sociales Universitat de Barcelona

1 de diciembre de 2019

\title{
EXPANSIÓN DE LA PRODUCCIÓN Y ESTANCAMIENTO DE LOS INGRESOS AGRÍCOLAS EN BRASIL: LATIFUNDIO Y PASIVOS TERRITORIALES COMO HERENCIA DEL PERÍODO POSNEOLIBERAL
}

\author{
Eliane Paulino \\ Universidade Estadual de Londrina (Brasil) \\ eliane.tomiasi@uel.br \\ Recibido 17 de julio de 2018; Aceptado 7 de diciembre 2018
}

\section{Expansión de la producción y estancamiento de los ingresos agrícolas en Brasil: latifundios y pasivos territoriales como herencia del período post-liberal (Resumen)}

Este artículo analiza los cambios del pacto agrario en el periodo posneoliberal instaurado en 2003 en Brasil y profundizados tras un controvertido proceso de destitución del presidente en 2016. Según la metodología basada en análisis de datos agrícolas, legislación y leyes del gobierno, la conclusión es que, en nombre de la seguridad jurídica para favorecer la agricultura y el desarrollo de un modo general, se está garantizando una involución sustancial en términos sociales y de protección al bien común, lo que aquí se concibe como pasivos territoriales de la política de inducción al acaparamiento de tierras públicas. Palabras clave: pacto latifundista, retroceso democrático, pasivos territoriales, acaparamiento de tierras

\section{Production and stagnation of agriculture inputs in Brazil. Territorial liabi- lities as the post-liberal heritage (Abstract) \\ This paper addresses the changes in Brazil's agrarian pact during to the post-neoliberal period established in 2003 and intensified after the controversial impeachment process of the president in 2016. Basing on the analysis of agricultural data, legislation, and go- vernmental acts, this paper shows that, in the name of legal security claiming to foster agriculture and development in general, a considerable involution is being imposed to the protection of social well-being; such an involution involves territorial liabilities of the policy that induces land grabbing.}

Key words: agrarian pact, democratic regression, territorial liabilities, land grabbing. 
Este texto tiene como propósito analizar el período reciente de la política agraria en Brasil, teniendo como punto de partida el período posneoliberal, cuyos fenómenos y procesos coinciden con la ascensión del Partido de los Trabajadores (PT) al poder. Una evidencia crucial que caracterizaría el momento aquí tratado tiene que ver con la combinación entre aumento desproporcionado de las inversiones públicas absorbidas por la agropecuaria, sin el retorno correspondiente, y el declive de la reforma agraria. Al igual que con otras promesas de campaña, la retórica prevaleció sobre la acción efectiva del Estado para enfrentarse a la elevada demanda de tierra. No se pretende sugerir que eso implicase una solución fácil, teniendo en cuenta la renuncia histórica del Estado brasileño a asegurar derechos territoriales primordiales de los pueblos originarios y a la negativa en favorecer el acceso para quien la trabaja.

La implementación del plan de gobierno demostró ser irreconciliable con los intereses de clase que, desde el comienzo, fueron amenazados por el proyecto de desarrollo inclusivo previsto. A pesar de todo, en algunos aspectos hubo progresos importantes, hasta el punto de que Brasil consiguió salir del mapa del hambre en 2014, según demuestra la Organización de las Naciones Unidas para la Alimentación ${ }^{1}$. Sin la pretensión de minimizar ese hecho tan significativo, y junto a otras conquistas sociales del período aquí designado como postneoliberal y que fue cerrado con la destitución de Dilma Rousseff en 2016, cabe situarlo en el vacío de intervenciones estructurales duraderas: la omisión de un reordenamiento agrario capaz de atenuar mínimamente la concentración territorial fue parte de ese corolario y, a nuestro modo de ver, la condición para el reposicionamiento de las demandas de clase contrarias al legado de la justicia social, recién ensayado en este lapso de tiempo. La cara más perversa de esa inversión no tardaría en aparecer pues, entre 2016 y 2017, entraron en condición de pobreza extrema nada menos que 1,5 millones de brasileños ${ }^{2}$. Las confrontaciones y los titubeos son parte de la apuesta por el favorecimiento del latifundio que, por determinación constitucional, debería ser eliminado para que las tierras ociosas pudieran ser destinadas a la reforma agraria. El incumplimiento reiterado de los parámetros de la función social que autorizan el derecho de propiedad está en la raíz de un modelo agrario incompatible con la justicia social y la salvaguarda ambiental en el país.

Ese derecho evoca restricciones que no pueden ser entendidas exclusivamente en el ámbito de la agricultura y en la lucha por la tierra, que son las abordadas en este texto que trata de distinguir la disputa entre tierra para realizar trabajo y tierra para explotar trabajo. Desde el punto de vista conceptual, se trata de distinguir la propiedad privada campesina y la propiedad privada capitalista, respectivamente, porque aunque campesinos y terratenientes vivan de la agricultura, son dos clases distintas que se oponen.

Pero hay que tratar también de los pueblos originarios y tradicionales, cuyo modo de vida implica un usufructo común y no el fraccionamiento de la tierra para

1 FAO, 2016

2 Villas Boas, 2018 
obtención del producto necesario para la reproducción social. Aunque se encuentra fuera de los marcos del mercado, la satisfacción de sus necesidades requiere la integridad de los biomas, con sus selvas, ríos y mares. Eso implica que la realización del trabajo propio se dé en la perspectiva del territorio y no simplemente en la de la tierra como propiedad privada.

No obstante, se trata de una demanda mucho más compleja en el contexto del modo capitalista de producción y no sería posible tratarla en este texto: las propiedades agrarias confieren la facultad individual sobre el suelo y eso tiende a confrontar la función social, sobre todo en aquello que es indispensable para esos pueblos. Pero, para ser exactos, eso no impide la convergencia de esos pueblos con la lucha emprendida por los campesinos contra los terratenientes, el enemigo de clase común para ambos; porque el foco en la tierra con el fin de explotar trabajo ajeno está en la raíz de la monopolización fundiaria y, en consecuencia, en la privación a su derecho de acceder a ella para realizar el propio trabajo.

Por eso, se trabaja en la perspectiva de los dos modelos de agricultura en disputa, el capitalista y el campesino, porque eso es decisivo para el bien común, entendiéndolo como indispensable no solamente para los pueblos del campo, sino también para todos los ciudadanos que, indistintamente, están en una estricta dependencia de unos entornos lo suficientemente íntegros, para proveer comida, agua y aire.

Una estrategia capaz de desencadenar un proceso de enfrentamiento contra aquello que más los amenaza, el monopolio fundiario implica, no obstante, un principio burgués primordial: la igualdad como criterio de abordaje del Estado con los campesinos y con los capitalistas del campo. Como se verá, en el período analizado, el gobierno profundizó aún más la distancia de esos que, por razones históricas, son absolutamente desiguales, reduciendo la proporción de las inversiones para los primeros y cambiando la legislación para favorecer los crímenes ambientales y la ocupación ilegal de tierras, en favor de los últimos.

Por eso, se hace necesario poner en tela de juicio la construcción de la ideología del agronegocio, que hace parecer que el problema de fondo del campesinado sea el escaso acceso a las tecnologías, cuando en realidad el riesgo permanente a su viabilidad económica es determinado fundamentalmente por la escasez de tierra.

La desigualdad, en su distribución y uso, impone lo que aquí es concebido como pasivo territorial, concepto que parece ser el más adecuado para posicionar 'la cuestión agraria', como una dimensión ampliada en relación a 'la cuestión agrícola'. Aunque sean diferentes, no hay que olvidar las correlaciones mutuas, poniendo especial atención para el significado de activo económico, pasivo ambiental y pasivo territorial.

Activo económico es un concepto perverso: sirve a la propagación de la ideología de clase gracias una supuesta universalización de las ganancias con la innovación tecnológica agrícola. El expansionismo inherente al agronegocio no es sino la negación de la función social de la tierra, pues sus límites reposan en las normativas del interés difuso que colisionan con derechos constitucionales. Segun Gras y 
Hernández ${ }^{3}$ su avance ocurrió pari passu a la capacidad de garantizar lucro y renta fundiaria mediante la reestructuración de clase. Para Almeida ${ }^{4}$ se ha traducido en un abordaje triunfalista del agronegocio articulada a una visión hiperbolizada de la potencia del campo.

Sin embargo, se trata de un pasivo con amplitud territorial, pues la función social constituye un principio fundamental de todas las sociedades democráticas: como contrapartida del derecho de propiedad, la función social supone obligación estricta para con el progreso social, lo que no coincide necesariamente con el progreso económico.

Como explica Mares ${ }^{5}$ el título de propiedad significa una autorización de uso compatible con los derechos ambientales y sociales de todos; por lo tanto, la agricultura no puede ser inscrita en el rol de las actividades productivas convencionales. Su singularidad recae en la facultad de movilizar a los dos únicos elementos capaces de producir riqueza: la tierra y el trabajo. Eso es lo que hace Marx ${ }^{6}$ cuando se refiere a un nivel de civilización en el que la propiedad privada parecerá tan monstruosa como la esclavitud humana, que es la propiedad de seres humanos por otros seres humanos. En sus palabras, la tierra no pertenece ni siquiera a una nación o a todas las sociedades de un determinado período histórico. Todos son usufructuarios y, en esa condición, tienen la obligación con las generaciones venideras de dejárselas, es decir, no comprometer el equilibrio compatible con el ciclo de la naturaleza.

Ciertamente, la agricultura concebida como negocio se opone a eso y en eso consisten precisamente los pasivos territoriales a los que nos referimos. Interpretarla según la perspectiva de los activos económicos tiene como horizonte lo inmediato y lo privado. Más allá de los aspectos productivo-mercantiles o de las funcionalidades sectoriales, una vez la agricultura surge como sector indispensable para el equilibrio de las finanzas y del propio engranaje de la economía, vale la pena reflexionar sobre las proyecciones mediáticas y los argumentos de autoridad académica aliñados ideológicamente con la llamada anti-agricultura, en palabras de Porto Gonçalves.

Como son las disputas en torno del bien común y del derecho difuso que las animan, se impone el análisis de la asimetría en la división del suelo, a pesar del notable desempeño agrícola en el período aquí analizado, en términos de expansión del área cultivada y del aumento de la productividad.

Como el volumen anual de las cosechas es susceptible a las condiciones climáticas del año agrícola, el recurso a la serie histórica ofrece una perspectiva de desempeño regular y, en ese caso, los números hablan por sí solos.

Como se verá a continuación, el período posneoliberal está marcado no solo por una meteórica expansión del crédito agrícola, sino también un destino discriminatorio del mismo en favor del empresariado rural en detrimento de la del campesina-

\footnotetext{
3 Hernández,2016

4 Almeida, 2010

5 Mares, 2003

6 Marx 1985, p. 891

7 Porto Gonçalves, 2006
} 
do, por lo que ha existido un retroceso significativo del área plantada con alimentos básicos, atribución fundamentalmente campesina.

De acuerdo con Bianchini ${ }^{8}$, en el primer año de la cosecha del nuevo milenio, con el auge de la política neoliberal de Fernando Henrique Cardoso, la agricultura empresarial se benefició con el 75,5\% de las inversiones estatales, una participación que aumentaría proporcionalmente, llegando al 86,6\% en 2015. Se trata de un triunfo de clase que explica la renuncia a la reforma agraria y la acumulación de pasivos territoriales traducidos en retrocesos en los marcos regulatorios de naturaleza ambiental y de la tenencia de la tierra.

\section{Lo agrícola y lo agrario desde un enfoque escalar}

A mediados de 2017, el anuncio de una cosecha récord de granos fue utilizado para atenuar la crisis política desencadenada por una sucesión de denuncias de corrupción que involucró a un sinnúmero de personalidades de los puestos más destacados del mundo corporativo y de la cúpula del gobierno, empezando por el presidente de la República.

Los tratos de favor a los sectores del campo acabaron por hacerse públicos por medio de delaciones a la justicia del presidente de JBS, la mayor empresa privada brasileña en términos de facturación, cuyo ramo de negocios se extendió a partir de la comercialización de carne bovina. Sus ingresos se multiplicaron por 42 en 10 años, lo que lo llevaría al segundo puesto del mundo en el sector alimentario, quedando atrás solo de Nestlé9.

Para ello, los recursos del Banco Nacional del Desarrollo Económico y Social fueron determinantes. Se trata quizá del caso más perturbador del discurso de la eficiencia empresarial, mostrado al público por las investigaciones de la Policía Federal, que alcanzaron gigantescas corporaciones y culminaron con el encarcelamiento de algunos de sus responsables. Es necesario decir que esa es la única novedad en los métodos históricos mediante los cuales los capitalistas alcanzan una situación de privilegio gracias al acceso privilegiado al fondo público, vía corrupción activa y pasiva de ocupantes de cargos y funciones estratégicas en el aparato de Estado.

La publicidad de tales métodos invita mínimamente al posicionamiento crítico en relación con el discurso hegemónico, en el que los buenos resultados en términos de cosechas pueden servir también para que poco o nada se investigue sobre la imposición de pérdidas severas en las arcas públicas, en el equilibrio ambiental, y en la seguridad laboral y social.

En el proceso que culminó en la destitución de la presidente electa, la clase terrateniente ha jugado un papel protagonista: los parlamentarios reunidos en el lobby más numeroso del parlamento brasileño, la Bancada Ruralista, lo defendieron oficialmente, entregando previamente para quien ocuparía su cargo un documento

8 Bianchini 2016, p. 107

9 Alvarenga y Gazzoni, 2017 
denominado Pauta Positiva ${ }^{10}$. El documento evocaba cambios en las normativas del derecho de propiedad en nombre de la seguridad jurídica, del medio ambiente, en nombre de la sostenibilidad económica y de las relaciones laborales, y en nombre de la generación de empleos en el campo. Ninguna de ellas podía ser implementada sin cambios legales sustantivos, incluso constitucionales. En el documento, firmado por 37 entidades de clase, se lee:

Como demostración de la ruptura con la actual política, plagada de ideologías contrarias al sector, y de la búsqueda de la reanudación del desarrollo económico, que seguirá siendo capitaneado por el sector agropecuario, las medidas inmediatas pasan por la garantía del orden público y de la seguridad jurídica. Y, de inmediato, por la mejora del ambiente de negocios, buscando principalmente la reanudación del sistema de crédito al sector, proporcionando el amplio acceso a recursos financieros en Brasil (públicos y privados) y en el Exterior ${ }^{11}$.

Paradójicamente, la misma semana en que el documento se hizo público, la presidenta había anunciado el Pla Zafra, aumentando los rescursos destinados a la agricultura hasta alcanzar la cifra de 57,3 mil millones de dólares estadounidense, el $87,3 \%$ de lso cuales se destinarían a los empresarios rurales ${ }^{12}$. Ese, que sería uno de los últimos actos antes de su destitución, muestra cuán sensible fue su gobierno a las presiones de los ruralistas, pero los resultados los justifican: la producción había aumentado exponencialmente tal como muestra la figura 1.

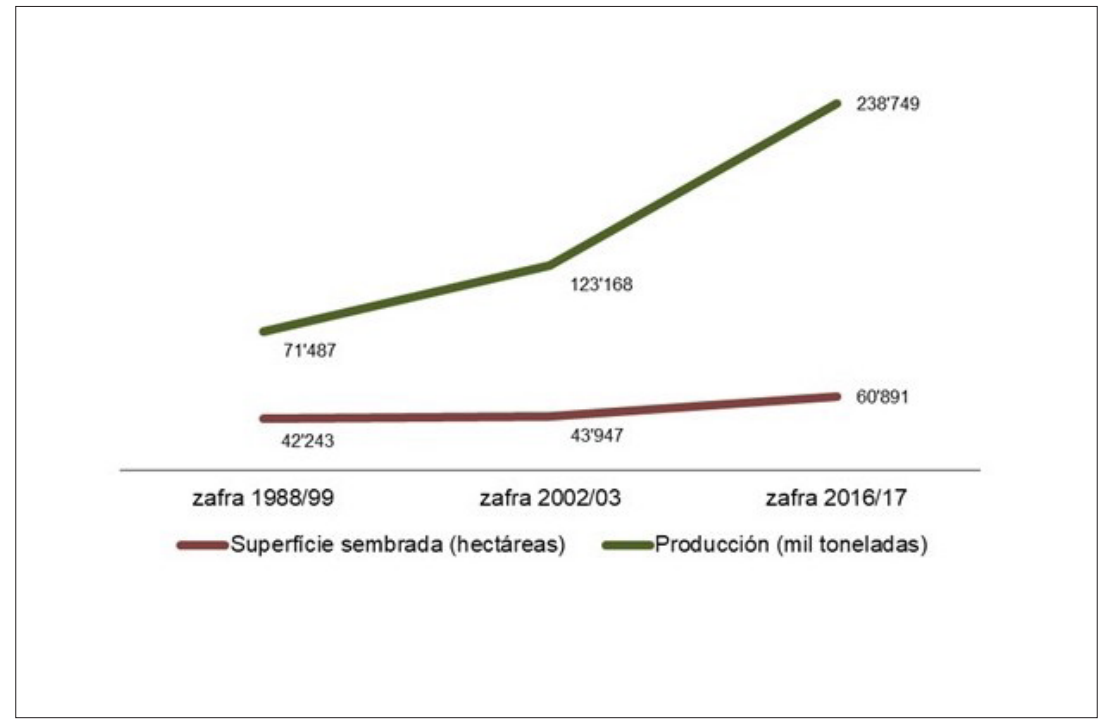

Figura 1 - Evolución de la zafra brasileña de granos Fuente: Conab, 2017.

El contraste con el lapso de tiempo comprendido por las cosechas 1988/99 a 2002/03 contradice los argumentos sobre la falta de inversión y la política de gobierno contradictoria a los intereses de los ruralistas, tal como queda descrito en el docu-

10 FPA, 2016

11 FPA, 2016, p.1

12 Brasil, 2017c 
mento mencionado. Su importancia reside, por lo tanto, en aquello que desmiente la razón alegada por los ruralistas para volverse grandes protagonistas de la campaña de intolerancia contra el gobierno PT, sus partidarios y hasta simpatizantes antes y después de la destitución. La ola de odio que dividió el país, y que no encuentra paralelo en regímenes democráticos, se revela, por tanto, como un instrumento útil cuando el criterio de las oportunidades de clase reclama golpes de Estado.

En ese sentido, la figura revela un dato cualitativo de extrema importancia: a pesar de la magnitud de la expansión de la agricultura, el área cultivada con granos ocupa menos del 7\% del territorio brasileño. Más aún, esa proporción requiere ser relativizada, porque está sobreestimada en virtud de la metodología de yuxtaposición utilizada en el cálculo de la Compañía Nacional de Abastecimiento ${ }^{13}$. Esta incluye solamente la estimación de la superficie cultivada por la extensión de cada cultivo y no por la proporción del territorio efectivamente destinado al uso agrícola.

Como las condiciones climáticas y técnicas hacen posibles dos cosechas anuales en el mismo lugar, pues el área cultivada con la labranza de verano es reutilizada en el cultivo de inverno, sería necesario utilizar el criterio de la superposición para evitar esa métrica equivocada sobre la superficie labrada del país. Tal ejercicio ofrecería mayor precisión para dimensionar la improductividad que, según la Constitución vigente, debe ser castigada con la desapropiación para destinar las tierras ociosas a la reforma agraria. De acuerdo con el Sistema Nacional de Casdastro Rural ${ }^{14}$ una superficie de 409.804 .598 hectáreas pertenece apenas a 93.385 propiedades. Juntos ocupan casi siete veces el área cultivada con granos en el país.

Es en ese contexto, de inmensas cantidades de tierras cultivables ociosas y en poder de pocos, que se está produciendo una mayor presión sobre los espacios protegidos, los territorios indígena y las poblaciones tradicionales. Eso solamente ha sido posible gracias a la alianza con el Estado brasileño. En vez de combatirlas, el gobierno posneoliberal la fortaleció, tanto que en ese período se intensificó la reprimarización de la economía ${ }^{15}$.

Si ni siquiera eso fue suficiente para satisfacer el apetito de los que se beneficiaron con ese proyecto, es porque se dieron las condiciones para precipitar la flexibilización de derechos, ya sean ambientales o territoriales, debidamente respaldados por el falso argumento de que era necesario aumentar la producción. Del mismo modo que no es la producción de mercancías lo que mueve a los capitalistas burgueses y sí la plusvalía que está en su origen, se puede afirmar que la apropiación privada capitalista de la tierra no está orientada primordialmente para el cultivo del suelo, aunque sea eso lo que hará mientras sea lucrativo.

No obstante, sus mayores triunfos son el acceso privilegiado a las arcas públicas y la renta del suelo, el lucro extraordinario de naturaleza independiente de la producción, porque deriva del derecho de monopolizar el espacio indispensable para

13 CONAB, 2017

14 INCRA, 2014

15 Delgado, 2010 
que los demás puedan vivir. El principio de la función social, previsto en la Constitución Federal, es el único capaz de disciplinar ese derecho descomunal, al obligar a los propietarios a retornar las tierras productivas, pero la ociosidad aquí demostrada es una evidencia de su descuido. Ocurre que la primacía del derecho absoluto de propiedad es una amenaza contra la civilización, pues

La tierra es solo otro nombre para la naturaleza, que no es producida por el hombre (...). Permitir que el mecanismo de mercado sea el único que dirige el destino de los seres humanos y de su ambiente natural, e incluso hasta del árbitro de la cantidad de uso del poder de compra, resultaría en el desmoronamiento de la sociedad. (...) ninguna sociedad soportaría los efectos de un sistema de semejantes invenciones, inclusive por un período de tiempo muy corto, a menos que su sustancia humana y natural, así como su organización de negocios, fuera protegida contra el asalto de ese molino satánico ${ }^{16}$.

Es en el sistema de monocultivos en el que la voluntad del mercado se realiza plenamente y su peor legado es el fenómeno de la concentración geográfica: solamente cuatro de los 27 estados de la federación brasileña (Mato Grosso, Paraná, Rio Grande do Sul y Goiás) superan, individualmente, la producción de cereales y de oleaginosa de las regiones sudeste, nordeste y norte juntas: en la cosecha de $2016 / 17$, respondieron por más de $68 \%$ de la colecta nacional de granos y, dentro de los cultivos, fueron responsables del $70 \%$ de la producción de soja, el cultivo que cubre el 56\% del área sembrada y es el producto de mayor importancia comercial del campo brasileño ${ }^{17}$.

Tomar esos datos por el sesgo de la producción sería lo mismo que asumir la ética métrica del capital como el mejor parámetro y horizonte de una sociedad. No obstante, eso dificulta el ejercicio a partir de la desproporcionalidad existente entre el dinero público capturado y el retorno en términos de renta agrícola traducida en el PIB. Adicionalmente, diversos estudios comprueban que la agricultura de pequeña escala no solo es más productiva, sino también más eficiente y próspera, social y ambientalmente hablando ${ }^{18}$.

Un ejercicio de escalas que permita una aproximación mejor a los hechos, puede ser realizado a partir del estado de Paraná. De acuerdo con el levantamiento del último censo disponible (2006), el 48\% de los dividendos de la producción agropecuaria provenían de las explotaciones de hasta 50 hectáreas, pero estas representan el 25,8\% del área agrícola cultivable declarada. Además, los ingresos de los establecimientos con más de 1.000 hectáreas fue de 347 dólares por hectárea, mientras que los establecimientos con menos de 10 hectáreas facturaron 1.699 dólares en igual fracción de tierra, o sea, cinco veces más ${ }^{19}$.

Eso parece ser una paradoja: frente a las supuestas ventajas objetivas de la agricultura capitalista, su ineficiencia inequívoca que muestran los datos. Tal como se

16 Polanyi, 1980, p. 85,86

17 CONAB, 2017, p. 26, 109

18 Rosset, 1999; Lutzemberger, 2001; Gimenez, 2006; Altieri, Funes Monzote y Petersen, 2011;Van der Ploeg, 2013; Hidalgo, Houtart y Lizárraga, 2014

19 IBGE, 2017 
ha indicado, se trata de una ineficiencia deliberada, pues surge de la decisión de mantener tierras ociosas, porque la renta de monopolio fluye independientemente del cultivo del suelo. Pero eso sería difícil si no se basara sobre una imagen de pujanza económica asociada a la gran propiedad.

Con excepción del recurso a la violencia, esa es la única estrategia capaz de remover del horizonte de una sociedad el clamor por la democratización de la tierra. No se afirma con esto que la estrategia sea nueva, pues Oliveira ya la analizaba detenidamente ${ }^{20}$, sino que la novedad radica en la magnitud que ha adquirido este proceso $^{21}$. Lo evaluado para el estado de Paraná no varía cuando se toma el promedio nacional o el promedio de los cuatro estados con agricultura más sobresaliente, como muestra la figura 2.

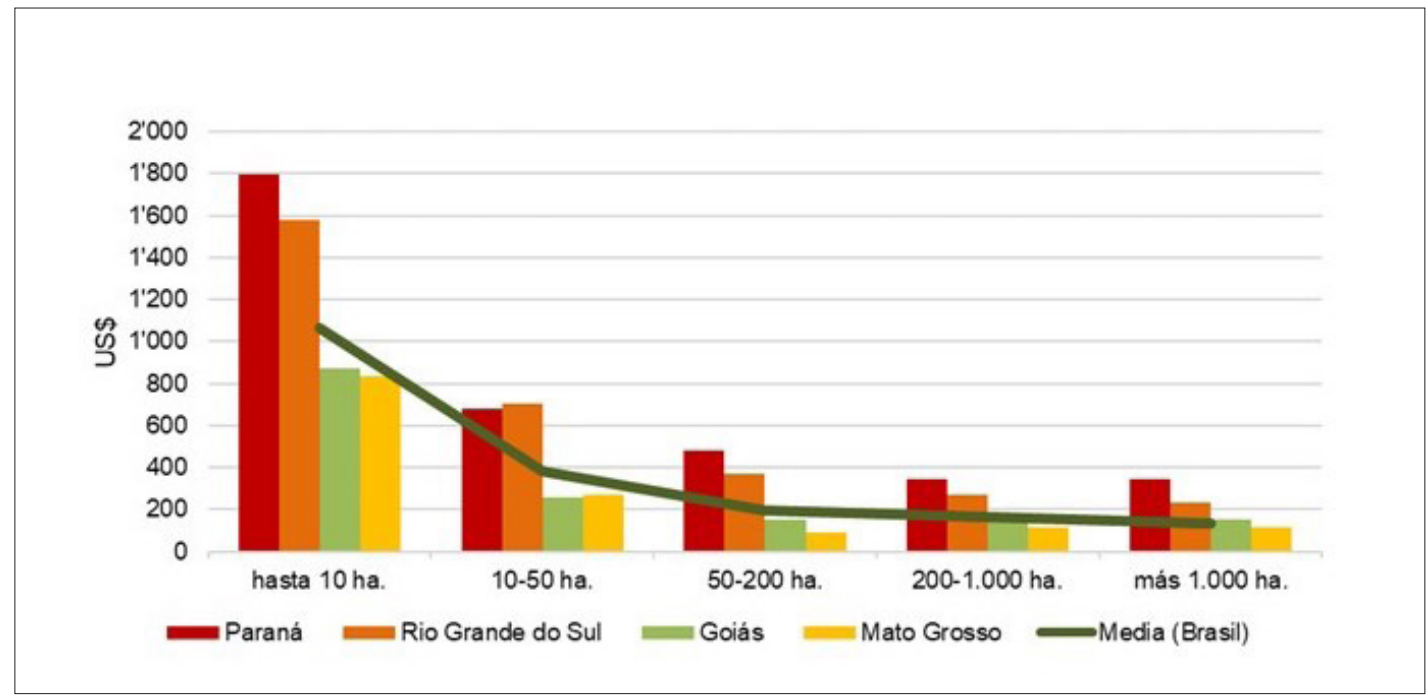

Figura 2 - Ingreso bruto anual según extensión media de las fincas (U\$/hectárea) Fuente: IBGE, 2017.

Solo cuando los datos se sitúan en términos de proporcionalidad de área agrícola a la que tienen acceso los terratenientes y el campesinado, se revela la respectiva eficiencia económica, cosa que la metodología de los cálculos econométricos desprecia completamente. Además, la eficiencia económica es solo una de las cuatro condiciones para la aplicabilidad del precepto constitucional de expropiación para fines de reforma agraria, que se traducen en el imperativo del cumplimiento de la función social de la tierra, fuertemente fragilizada en el período posneoliberal. El gobierno utilizó una combinación de estrategias, a saber: a) desmantelamiento de los movimientos sociales mediante la cooptación de líderes, mediante la contratación temporal para actuar principalmente en funciones relacionadas con programas y proyectos agrarios; b) profundización de políticas asistencialistas; c) represión de la lucha y criminalización de los trabajadores; d) ideología del fracaso de la reforma agraria y de la robustez económica de la gran propiedad. Estas elecciones políticas se tradujeron en políticas territoriales que estimularon el aumento de la concentración 
de la tierra, gracias a la legalización de la ocupación ilegal, combinados con el retroceso de las acciones de expropiación para fines de reforma agraria ${ }^{22}$.

Por eso, no sería suficiente analizar la concentración de la tierra solo en el aspecto económico, de la agricultura en sentido estricto, sino lo que definimos como uso del suelo, porque hay en ello una cuestión trascendente: el campo expresa ineludiblemente lo que es el territorio. Como señala Raffestin ${ }^{23}$, es en los marcos de las relaciones de poder cuando se obtienen los triunfos territoriales. El debilitamiento de los movimientos sociales fue decisivo para el fortalecimiento del latifundio que, a su vez, dialécticamente, disfrutó de ese beneficio influenciando las decisiones y acciones políticas en su favor. Como se verá más adelante, la reforma agraria fue abandonada en la agenda política, al tiempo que se fueron aprobando leyes para reglamentar la ocupación ilegal de las tierras públicas, donde deberían estar a salvo las unidades de conservación ambiental y los territorios de vida de los pueblos originarios y tradicionales.

La dictadura del desarrollismo agrícola consiguió conquistas que son incompatibles con el momento de consciencia planetaria sobre la crisis ambiental, hasat el punto de justificar incluso la derogación de una Ley Ambiental más amplia, y cuya victoria más expresiva fue la absolución automática de todos los que la infringieron, independientemente de la extensión, frecuencia y naturaleza del crimen ambiental cometido. La nueva ley no solo atenúa el carácter protector del bien común sino que lo corrompe, al permitir que los propietarios cobren a la sociedad para cumplir la ley, mediante el pago por servicios ambientales, ese bien intangible del que nos hablan Marés, Polanyi y Marx ${ }^{24}$.

Fue en nombre de los campesinos que esa ley triunfó y la mayoría de los campesinos la recibió como si fuera un derecho. Pero la derrota de la función social de la tierra es la victoria del negocio fundiario, incompatible por naturaleza con los territorios de la vida y con la tierra de trabajo, aún más con la propiedad campesina.

La tesis de los juegos que no suman cero de Raffestin ${ }^{25}$ nos ayuda a comprender ese momento, pues aunque se trate de una situación tan asimétrica, los beneficios no fueron totalmente para los propietarios capitalistas. Fue en el período posneoliberal, es decir de 2003 a 2016, cuando se dio una reversión relevante en la historia del descuido de la agricultura campesina: se adoptaron importantes políticas inéditas para fortalecerlas, y eso fue posible incluso con el 7,9\% de los recursos captados por los productores.

La instauración de mercados institucionales, en que el gobierno garantiza la compra de una parte de la producción a precios similares a los que se encuentran en el menudeo, son el mejor ejemplo. De acuerdo con Bianchini ${ }^{26}$, de 2003 a 2016 se inviertieron cerca de 3,1 mil millones de dólares en el Programa de Adquisiciones

22 Santos, 2017; Sobreiro Filho et al, 2018

23 Raffestin 1993

24 Mares, 2003; Polanyi, 1980; Marx, 1985

25 Raffestin, 1993

26 Bianchini, 2018 
de Alimentos (PAA). La descentralización de las acciones, con la transferencia de los recursos para que los municipios comprasen la producción campesina local para destinarla a entidades públicas o asistenciales locales, hizo con que muchas familias vieran ahí la oportunidad de diversificar la producción y aumentar sus ingresos ${ }^{27}$.

Más robusto en términos de inversión, el Programa Nacional de Alimentación Escolar (PNAE) pasó a exigir que todos los municipios compraran a los campesinos un mínimo del 30\% de los alimentos que se servían para todos los estudiantes de la educación básica de la red pública: por lo tanto, en el período de 2003 a 2015 fueron invertidos aproximadamente 13,2 mil millones de dólares ${ }^{28}$.

Estos programas inauguraron en Brasil un mercado institucional capaz de generar impactos que no pueden ser valorados solo desde el punto de vista económico. Un estudio realizado por $\mathrm{Coca}^{29}$ en una cooperativa de asentados de la reforma agraria en el estado de Paraná identificó que en paralelo con el aumento de la renta monetaria, el programa favoreció la diversificación productiva con mejoramiento de la alimentación de las familias, la valorización del trabajo de las mujeres y el fortalecimiento de las prácticas colectivas. Al investigar el Territorio de la Ciudadanía Integración del Norte Pionero de Paraná, Nunes ${ }^{30}$ verificó que, dentro de las familias beneficiadas por ambos programas, los ingresos familiares habian aumentado en promedio $30 \%$.

Además de los ingresos, otros beneficios identificados fueron la diversificación de la producción y del consumo familiar, el estímulo a la producción de alimentos orgánicos, como demostró Pugliesi ${ }^{31}$ al estudiar cooperativas proveedoras de alimentos para el PNAE.

Estos son ejemplos de algunos avances de ese período, ínfimos hay que decir, ante el aporte público a la agricultura capitalista: entre 2003 y 2016, fueron destinados para la financiación e inversión de la agricultura capitalista 714,3 mil millones de dólares, mientras que a la agricultura campesina le correspondió apenas 61,4 mil millones de dólares, o sea, el 92,1\% del monto fue destinado a la primera ${ }^{32}$.

La insatisfacción de los ruralistas, por lo tanto, no se explica por la fracción que les correspondió del fondo público, y sí por la presunción de que solamente ellos tienen el derecho a su acceso. Emana, por tanto, de la lucha de clases, la síntesis de los intereses en colisión que instauraron la disputa abierta, cuya culminacion sería la imposición de un gobernante no electo en la presidencia.

En ese contexto de aumento del latifundio, la Constitución fue modificada para permitir la congelación de las inversiones en servicios públicos esenciales por 20 $a_{n} \operatorname{sos}^{33}$ y está siendo resucitada una agenda política aliñada con la paralización de

27 Viegas, 2017

28 FNDE, 2017

29 Coca, 2015

30 Nunes, 2015, p. 6

31 Pugliesi, 2015

32 Bianchini, 2016, p. 106

33 Brasil, 2016 
políticas redistributivas que, a ejemplo de las anteriormente mencionadas, son parte del Programa Nacional de Fortalecimiento de la Agricultura Familiar, en el contexto de la cual tales aportes fueron posibles.

A pesar de que los datos sean indiscutibles desde el punto de vista de la insuficiente respuesta de la agricultura capitalista ante el volumen de las inversiones públicos del período, la ideología del agronegocio prosperó gracias a trabajos supuestamente científicos que, sin el necesario rigor metodológico y sin el respaldo estadístico de los datos oficiales, difunden la tesis de la eficiencia y de la autosuficiencia de los empresarios rurales ${ }^{34}$. Sin la invisibilización del campesinado y la descalificación de los estudios agrarios, no habría sido posible hacerlo. La figura 3 está construida a partir de dos elementos mensurables: el valor de crédito rural obtenido y los ingresos del sector valorados por el PIB, correspondiente al año en el que los préstamos fueron adquiridos.

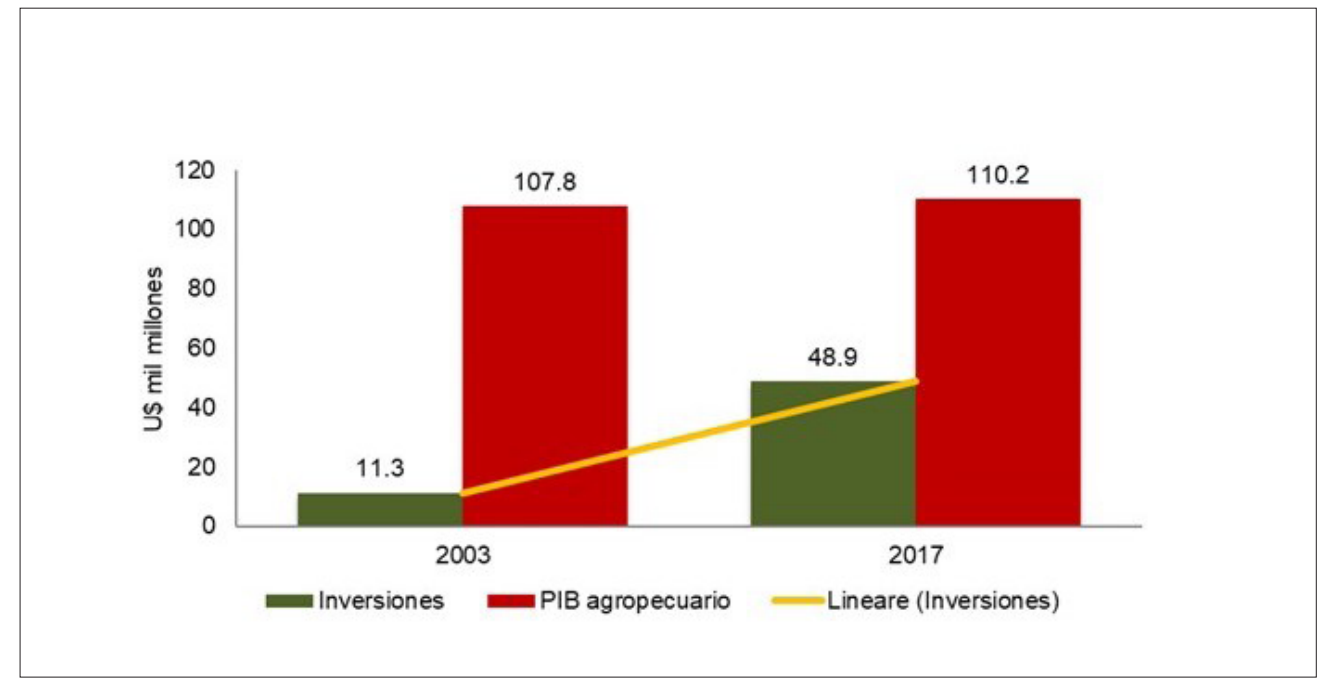

Figura 3 - Inversiones estatales y PIB agropecuario en Brasil (U\$ mil millones) Fuente: BACEN, 2018; CEPEA, 2018.

La relación directamente proporcional entre crecimiento de los recursos captados por los propietarios emprendedores y rentistas, y su insatisfacción con el gobierno podría parecer hasta ingratitud, pero la teoría de la acumulación ampliada no tolera una mirada moral sobre la expresión concreta de las asimetrías de clase.

Cabe aclarar que los ruralistas, así como los capitalistas rentistas y tantos supuestos burgueses, se rebelaron contra los gobernantes que, ajenos a su ineficiencia en generar una riqueza proporcional a las inversiones públicas, abrieron los cofres del Estado. El monto de crédito rural obtenido se cuadruplicó, mientras que el PIB apenas creció un 2\% en el período: por cada dólar prestado con tasa subsidiada, la agropecuaria produjo U\$ 9,54 en 2003, mientras que en 2017 sólo logró producir U\$ 2,25 .

La mejor explicación de esta aparente paradoja es la lógica de clase que, además, viene siendo expresada en forma de odio e intolerancia. Ante un futuro que parece

34 Por ejemplo, Buainain, Alves, Silveira \& Navarro, 2013 
amenazador, las evidencias del presente son suficientemente indicadoras de que las migajas que se dan a la agricultura campesina, como a los pobres en general, no han pasado de un destello en la línea del tiempo, porque los cambios administrativos como la extinción del Ministerio de Desarrollo Agrario y los cambios en curso, afectarán duramente a los campesinos y, con ellos, la economía de la mayoría de los municipios brasileños, como bien señala Arrais ${ }^{35}$.

\section{La paradoja de la miniagrarización y la empresarialización del latifundio}

Entender la empresarialización del latifundio pasa por la correlación entre activos y pasivos a ser gestionados por una sociedad, en la exacta medida en que se trata de las cargas y de los bonos de la agricultura. Según Oliveira ${ }^{36}$, el Gobierno mantuvo la opción por un modelo agrícola enfocado a la demanda del mercado global y a la generación de divisas, con el precio del suministro de alimentos y demás bienes esenciales a través de importaciones.

Sus ideólogos también se burlaron de las correlaciones mínimas sobre los despliegues que ello tendría en términos territoriales, empezando por el hecho de que, en la economía de mercado, el abastecimiento es un punto de una cadena cuyo funcionamiento perfecto instituye como elemento de primera magnitud la accesibilidad, primero de quien produce y, segundo, de quien compra.

De acuerdo con Mazoyer y Roudart ${ }^{37}$, las tres cuartas partes de los que padecen hambre en el planeta viven en el campo, oprimidos por la falta de tierras y por la cadena de carencias que ello provoca. No se pretende, por tanto, tratar a Brasil como una excepción, sino entender su especificidad. La propia situación de América Latina es la evidencia de una diversidad forjadora de la unidad: no bastase ser esa la región con el mayor índice de concentración de la tierra del planeta, un estudio de Jara, Rodríguez Sperat y Rincón Manrique ${ }^{38}$ sobre los desdoblamientos de las políticas neoliberales travestidas de desarrollistas sobre Argentina y Colombia en el mismo período aquí estudiado, no sólo mostró una enorme semejanza en términos de políticas específicas para el campesinado, sino también su inocuidad en vista de la hegemonía del latifundio en el aparato de Estado.

El último levantamiento censal de Brasil mostró que aproximadamente el 53\% de las fincas tenían un área media inferior a tres hectáreas ${ }^{39}$. Objetivamente, su viabilidad económica está condicionada a una sola actividad: la producción hortigranjera, pero no hay mercado para todos. Se sabe que sólo las localizaciones geográficas privilegiadas podrían proporcionarlo, pero la red urbana es muy desigual, con algunas ciudades muy extensas y muchas pequeñas, sin un mercado consumidor relevante.

35 Arrais 2017

36 Oliveira, 2016

37 Mazoyer y Roudart, 2010

38 Jara, Rodríguez Sperat y Rincón Manrique, 2014

39 IBGE, 2017 
Eso explica lo que se expresa en la literatura como pérdida de producción en perfectas condiciones de consumo, por el simple hecho de que la produccion no está compensada por los costes de transporte hasta su destino final.

El territorio brasileño, donde la accesibilidad es condición de una geografía cuyo contenido agrario viene, fundamentalmente de la miniagrarización es, además, mucho más extenso. La medida establecida por las normativas como límite de fraccionamiento para los cultivos perennes es de 10 hectáreas. Como resultado, el $83 \%$ de las fincas en Brasil estarían limitados a la horticultura o al cultivo de culturas perennes para que sean económicamente viables ${ }^{40}$.

La participación minoritaria de cultivos perecederos y perennes en términos de posibilidades de envío, absorción por el mercado y generación de ingresos anuncian la esencia de un problemo agrario no tratado incluso en el tiempo que prometía ser posible: el interdicto a la producción de commodities se determina por la insuficiencia de tierras, siendo este uno de los obstáculos para que el campesinado se beneficie de las macroestructuras implementadas para ese fin.

Contrariamente a un ordenamiento agrario que favoreciera la desconcentración y estuviera vinculado a políticas públicas preferenciales para esa clase, empezando por el crédito, retornó con una fuerza excepcional la estrategia republicana de hacer esfuerzos institucionales para reconocer como patrimonio privado las tierras públicas apropiadas ilegalmente, ahora asociada con otra estrategia socialmente comprometedora: el debilitamiento de los marcos legales para una conducta ambientalmente correcta en el campo en términos de la función social de la tierra.

Podría afirmarse que el conjunto de leyes vigentes es la mejor expresión de los consensos de cada sociedad en cada tiempo histórico. De la misma manera, la capacidad de burlarlas es la mayor evidencia de cómo actúan las fuerzas que les son contrarias. Al afectar el marco legal nos muestran en la práctica cómo se imponen las hegemonías: la eliminación de las leyes incómodas tanto quita el testimonio de los crímenes otrora cometidos, como crean una institucionalidad más conveniente para los intereses movilizadores de clase.

Esto es lo que permitió, sin perjuicios relevantes, la constitución del patrimonio de la tierra privada mediante la sistemática violación de los preceptos del derecho de propiedad instituidos en 1850 por la Ley 601. En su artículo segundo, se expone:

Los que se apoderen de tierras que deberían devolverse al Estado o a alguien, y en ellas derriban árboles o los queman, serán obligados al desahucio, con pérdida de lo que haya hecho en la propiedad, y también sufrirán la pena de dos a seis meses de prisión y multa de 100 , además de la satisfacción del daño causado. $\left({ }^{41}\right)$.

Se agrega que desde 1934, año además en el que se sanciona el Código Forestal Brasileño, el requisito de la función social de la tierra a la que está ligada la tutela ambiental es una constante en las Cartas Magnas.

40 IBGE, 2017

41 Brasil, 1850 
Sin embargo, la justificación de instaurar la seguridad jurídica para profundizar las medidas de protección ambiental en la Amazonia ha traído consigo la sanción de la única legislación a favor de la ocupación ilegal de tierras, desde el blindaje del latifundio en la época de la transición del trabajo esclavo hacia el trabajo libre, expresada en la Ley 601 anteriormente mencionada.

Le bastó al gobierno ignorar un principio vigente desde 1850 con la institución del régimen de propiedad privada en Brasil: la tipificación de la posesión. La cláusula pétrea de las Constituciones brasileñas, de la que derivan los parámetros de fraccionamiento mínimo anteriormente mencionados, es la del dimensionamiento según una medida capaz de ocupar y permitir el sustento de una familia que viva y trabaje en ella. Según la Constitución vigente, toda tierra rural pública de hasta 50 hectáreas, cuando es explotada por la familia que vive allí, es susceptible de legalización por medio de una concesión de derecho real de uso.

Si bien ninguna ley ordinaria pueda ser contraria a una Constitución, este es uno de los casos en que su conversión en letra muerta resulta en una herencia de las más deletéreas: en 2009 la Ley amplió a 1.500 hectáreas la fracción de tierra pública susceptibe de concesión de derecho real de uso, o sea, de los derechos de propiedad. (Brasil, 2009a). Tal provocación a la Constitución fue objeto de una Acción Directa de Inconstitucionalidad ${ }^{42}$, pero hasta el momento no ha sido juzgada por la suprema corte nacional. Con el inmovilismo de la esfera jurídica capaz de frenar tal usurpación al patrimonio público, en 2017 fue sancionada una Ley que ampliaba a 2.500 hectáreas la extensión legalizable de las tierras robadas por los invasores ${ }^{43}$ y en 2018 se publicaron los Decretos regulando esa ley ${ }^{44}$.

Es ese pacto lo que explica la composición de las fuerzas políticas que vienen manteniendo en el poder a un presidente instaurado por medio de un golpe parlamentario y motejado a partir de robustas denuncias de corrupción.

Mientras la Procuraduría General de la Unión se encuentra intentado revertir tal crimen sin éxito, líderes indígenas, campesinos, sindicalistas e intelectuales también vienen tratando de concienciar a la sociedad sobre la gravedad de las leyes de encargo para los grandes invasores de tierras, pero en Brasil la fuerza del latifundio no es poca. A su servicio hay científicos y formadores de opinión de las tribunas virtuales para bloquear el acceso al conocimiento, una opresión adicional para la sociedad marcada por innumerables asimetrías y que son todavía más acentuadas en Brasil que en Argentina, Colombia y Sudáfrica, como muestra la figura 4.

Por el momento, la población en general sigue ajena a las implicaciones del cambio agrario relativas a la profundización de la concentración de renta y patrimonio en Brasil. Lo mismo puede decirse en relación con la cuestión ambiental, frente al inmovilismo nacional ante la destrucción de patrimonio público de inconmensurable valor, los bosques y otros bienes ambientales. Bajo la Ley $12.651^{45}$, y de una

42 Brasil, 2009b

43 Brasisl, 2017

44 Brasil, 2018a, 2018b, 2018c

45 Brasil, 2012 
sentencia de constitucionalidad emitida en febrero de 2018 por la suprema corte nacional, el Estado no sólo legalizó el perdón de los crímenes ambientales, también amplió el margen para su práctica, al desfigurar la avanzada legislación vigente desde $1934^{46}$.

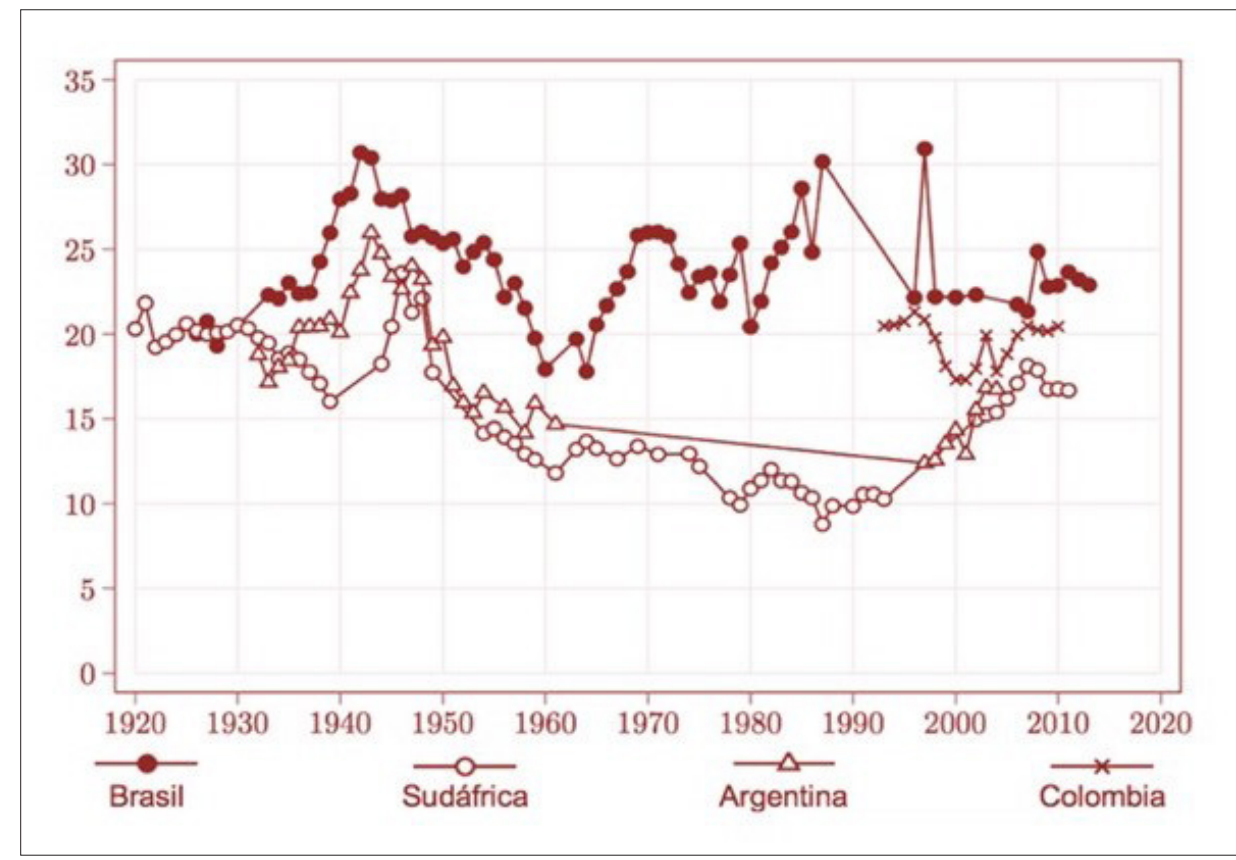

Figura 4-Participación del 1\% de los más ricos en el reparto de los ingresos nacionales (\%)

Fuente: Souza, 2016, p. 246.

Esas son pruebas del retroceso en el tiempo, en términos de la alianza para el atraso a que se refería Martins ${ }^{47}$, aún más fortalecida bajo la presidencia de Michel Temer que, en 2017, ya logró aprobar normativas comprometedoras, con relación al medio ambiente como la Medida Provisoria 756 y el Decreto 9.142, los cuales extinguen reservas ambientales en la Amazonia para favorecer tanto a invasores ilegales como a empresas mineras ${ }^{48}$. Mientras tanto, tales hechos se encuentran sub judice, al haber acciones en la justicia intentando derrocarlas e incluso retrocesos del presidente vía decretos, pero la composición de fuerzas no da indicios animadores en este sentido.

\section{A modo de cierre}

La concentración del uso de la tierra, propiciada por el cambio técnico y la progresiva exclusión que el imperativo del mercado global impone, se dio dentro de un contexto de vulnerabilidad que no es solo del modo campesino de producir en el campo. Paralelamente, el debilitamiento de los ecosistemas a escala planetaria se dio al mismo ritmo, amenazando severamente los pueblos que constituyen los terri-

46 Casado, 2018

47 Martins 1994

48 Brasil, 2017 
torios de vida fuera de los marcos del mercado. Eso revela la complejidad de los vínculos para que todo confluyera en beneficio de la acumulación de capital en escala ampliada, en cuyo centro está justamente la mercancía, el mecanismo mediante el cual la plusvalía se realiza.

Sin embargo, las características de la mercancía se determinan por la geografía de los lugares, porque la ocurrencia de los bienes pasibles de uso comercial no se define por las fuerzas del mercado, sino por las de la naturaleza, siendo las formas y el ritmo de apropiación una ecuación determinante y determinada por el valor de cambio inherente a los recursos allí existentes, así como su lugar en la división territorial del trabajo. En esta zaranda prevalece el imperativo de la transformación cada vez más acelerada de bienes naturales en mercancías, a través de la única fuerza creativa posible, el trabajo humano.

No por casualidad, los principios contemplados en planes de desarrollo gestados en el interior de organismos multilaterales, en general reiterados en el plano del discurso por los gobiernos nacionales de el período post-neoliberal, centran el foco en dos frentes básicos de acción social y sostenibilidad ambiental. Esta proyección revela que esos son los aspectos más prominentes en el conjunto de las contradicciones generadas en el seno de las relaciones de producción, ya que el trabajo y los bienes gratuitos de la naturaleza susceptibles de ser convertidos en valores de uso, están siendo desechados en el contrato societario instituido en nombre de la racionalidad del mercado, a punto de inviabilizar un horizonte de civilización longevo.

Lo que conviene a los terratenientes y a los burgueses, de modo general, atenta contra los intereses de los campesinos, de los pueblos originarios y tradicionales, así como a los demás trabajadores. Son ellos quienes extraen plusvalía, directamente, por medio de relaciones de recepción de salarios e indirectamente, por medio de la obtención de la riqueza social a través de la tributación extraordinaria, la renta de la tierra. Empero los campesinos también se encuentran oprimidos por diferentes mecanismos de usurpación. Distinguir tales agentes no siempre es posible, particularmente en Brasil, ya que los terratenientes eventualmente son industriales, banqueros, grandes comerciantes, siendo la recíproca verdadera, pues cada vez más la diversificación de los negocios pasa a ser una estrategia importante para el blindaje contra los riesgos. Por definición, en las confrontaciones de clase sus oponentes son los campesinos, los trabajadores y los pueblos tradicionales y originarios que, a su vez, libran batallas distintas, sin que eso signifique estar en otra trinchera.

De este modo, las dos clases que componen el bloque hegemónico de la sociedad, los terratenientes y los propietarios de los demás medios de producción dividen entre sí la riqueza excedente, lo que no significa que sea la que sobra, sino la que se extrae a expensas de condiciones mínimas de existencia de sus productores inmediatos. No conviene omitir también la riqueza extraída anticipadamente de las generaciones venideras, que vendrán a un mundo marcado por un débito acumulado en pasivo ambiental. 
De algún modo, tendrá que ser enfrentada, sea con gasto ampliado de energía vital, porque la labor en el necesario intercambio con la naturaleza para la provisión de las necesidades inalienables se dará en condiciones más desventajosas que las actuales; sea con la vida en sentido estricto, donde y cuando esta sea abreviada por la ausencia de lo mínimo indispensable, como agua potable, alimentos y todas las violencias que ello impone, incluso porque los impactos no se distribuyen democráticamente. Los campesinos, los indígenas y las poblaciones más pobres de las franjas urbanas son las mayores víctimas de la degradación ambiental.

La coalición de intereses de clases ha sido capaz de poner en el plano secundario diferencias intrínsecas, a ejemplo de la perpetuación del tributo materializado en la renta de la tierra, que si en un primer momento resistió al modo capitalista de producción delante de la necesidad de la propia burguesía de tener a su disposición el ejército industrial de reserva, evolucionaría para una etapa en que se vuelve instrumento de acumulación por medio del sesgo rentista, el mismo que está en la raíz de la financiarización de la economía, cuyo potencial desestabilizador apenas empieza a ser sentido, ya que especular se ha convertido en uno de los negocios más lucrativos en la actualidad y eso no se restringe solo a la tierra.

Siendo así, en común o por referéndum, cualquier mecanismo institucional que pueda perpetuar supremacías será utilizado y toda oposición será combatida, siendo la represión social y la violencia la estrategia final, cuando no haya más espacio para mediaciones, pues como recordó Arendt ${ }^{49}$, una evidencia de pérdida de legitimidad en el ejercicio del poder es el uso de la fuerza.

Por eso, al prevalecer el imperativo de la acumulación ampliada de capital, toda propuesta de gestión transformadora será rechazada o amputada, convirtiéndose en la mejor de las hipótesis en paliativos que no tienen como modificar los procesos estructurales, pues estos están constituidos por los engranajes voraces de la acumulación ampliada, cuya fuerza destructiva se ha ampliado progresivamente, como defiende Bartra ${ }^{50}$.

Esta problemática no permite enfoques estructuralistas, como si hubiera un proceso de sentido único, pues eso sería lo mismo que negar el más básico principio de la dialéctica, la contradicción, que invariablemente se manifiesta en la compleja dinámica del ejercicio del poder, en el que se enfrentan resistencia, combate y adhesión a los dictámenes del capital. Reconocer su hegemonía, dadas las relaciones asimétricas trabadas en el seno de la sociedad en el proceso de producción material y la reproducción social, no es lo mismo que caer en la trampa abstraccionista que la confunde con homogeneidad, porque es precisamente en la disidencia que es posible construir caminos para su superación.

El cambio de la legislación y los argumentos aquí debatidos son una evidencia de ello, pues el frágil margen de control social sobre el uso de la tierra y de los recursos naturales de Brasil se debilitó por el protagonismo del pacto rentista, producto 
de la alianza entre tierra y capital que, por otra parte, es la inductora de las asimetrías en la división de la tierra y del fondo público para el fomento de la agricultura.

Este es el detalle que se les escapa a los teóricos que siguen analizando la tierra como un medio de producción semejante a los demás, cuando en realidad ella es equivalente de capital, dado que ahí la riqueza fluye por dos vías, la producción, cuando la hay, y la renta, aunque la producción no exista. Este es su diferencial, que implica en acaparamiento de la riqueza social sin haber necesariamente ninguna intervención directa. Eso explica la furia del acaparamiento sobre las tierras campesinas, indígenas y de las demás poblaciones tradicionales en ascenso en Brasil.

En esto reside el pasivo territorial impuesto por la convergencia de intereses traducidos en nuevos contornos de la hegemonía de clases aquí presentada. Cierto es que tendrá que ser confrontado en algún momento por esta sociedad encantada con la creencia en el futuro, pero ahora paralizada por el apercibimiento del presente. Los presagios del orden y del progreso salidos de la bandera de Brasil acompañan el eslogan presidencial cuya misión no deja dudas: excluir y dilapidar, porque de ello vive el capital en su intrincada alianza con el latifundio.

\section{Bibliografía}

ALMEIDA, A.F. B. Capitalismo globalizado e recursos territoriais. Rio de Janeiro: Lamparina, 2010.

ALTIERI, M.A.; FUNES MONZOTE, F.R.; PETERSEN, P. Agroecologically efficient agricultural system for smallholder farmers: contributions to food sovereignty. Agronomy for Sustainable Development, 2011, núm. 32, p. 1-13.

ALVARENGA, D.; GAZZONI, M. Com ajuda do BNDES, donos da JBS criaram maior empresa de carnes do mundo. Jornal O Globo de 12 mayo 2017. <http://gl.globo. com/economia/negocios/noticia/com-ajuda-do-bndes-donos-da-jbs-criarammaior-empresa-de-carnes-do-mundo.ghtml> [11-11-2017].

ARENDT, H. A condição humana. 10. ed. Rio de Janeiro: Forense Universitária, 1989.

ARRAIS, T.A. Risco social no espaço rural: a reforma previdenciária e o fim da aposentadoria rural. Goiânia: UFG, 2017.

BACEN. Banco Central do Brasil. Crédito rural: quantidade e valor dos contratos por município. Brasília: Bacen, 2018. <http://www.bcb.gov.br/pt-br\#!/r/ micrural $/$ ? path=conteudo\%2 FMDCR \%2FReports \% 2FqvcMunicipio. rdl\&nome=Quantidade $\% 20$ e $\% 20$ Valor\%20dos\%20Contratos\%20por\%20Muni c\%C3\%ADpio\&exibeparametros=true\&botoesExportar=true $>$ [04-04-2018].

BARTRA, A. El hombre del hierro: los limites sociales y naturales del capital. México: Itaca, 2008.

BIANCHINI, V. Vinte anos do PRONAF 1995 - 2015: avanços e desafios. FAO: Family Farming Knowledge Platform, 2016. <http://www.fao.org/family-farming/detail/ en/c/328528/> [11-09-2016].

BIANCHINI, V. Análise do programa de aquisição de alimentos da agricultura familiar: PAA. Boletim FAO Comunicação e Informação, 2018, núm. 223, p. 1. 
<http://boaspraticas.org.br/index.php/pt/informativo-fao-brasil/747-c223> [05-05-2018].

BRASIL. Ley 601/1850, de 18 de septiembre, de Tierras. Secretaria d'Estado dos Negocios do Imperio, 2 de octubre de 1850, fl. 57 libro $1^{\circ}$ de los Actos Legislativos. BRASIL. Decreto 23.793/1934, de 23 de enero, del Código Florestal. Diário Oficial da União, Seção 1, 09 de febrero de 1934, p. 2882.

BRASIL. Ley 11.952/2009a, de 25 de junio, de Regularição Fundiária. Diário Oficial da União, 26 de junio de 2009, seção 1. p. 1.

BRASIL. ADI 4269/2009b, de 09 de julio, de Inconstitucionalidade. Supremo Tribunal Federal, 30 de octubre de 2017, Ofício 23606/2017, Certidão de Julgamento Js956231631br.

BRASIL. Ley 12.651/2012, de 05 de mayo 2012, de Novo Código Florestal. Diário Oficial da União, 03 de junio de 2012, seção 1. p. 1.

BRASIL. Enmienda Constitucional 95/2016, de 15 de diciembre 2016, de Teto Gastos Públicos. Diário Oficial da União, 16 de diciembre de 2016, seção 1, p. 2.

BRASIL. Decreto 9.142/2017a, de 22 de agosto 2017, de Extinção de Reserva Nacional. Diário Oficial da União, 23 de agosto de 2017, seção 1, p. 1.

BRASIL. Ley 13.465/2017b, de 11 de julio 2017, de Regularição Fundiária. Diário Oficial da União, 12 de julio de 2017 rectificado en 06 de septiembre de 2017 y publicado cómo texto consolidado en 08 de septiembre de 2017, seção 1, p. 1 .

BRASIL. Plano Safra 2016-17, de 08 de mayo de 2016c, de Financiamento. Ministério da Agricultura, Pecuária e Abastecimento, de 08 de mayo de 2016. <http://www. agricultura.gov.br/assuntos/sustentabilidade/plano-abc/arquivo-publicacoesplano-abc/PAP1617.pdf> [19-05-2017]

BRASIL. Decreto 9.309/2018a, de 15 de marzo de 2018. de Regularição Fundiária. Diário Oficial da União, 16 de marzo de 2018, seção 1, p. 1 .

BRASIL. Decreto 9.310/2018b, de 15 de marzo de 2018. de Regularição Fundiária. Diário Oficial da União, 16 de marzo de 2018, seção 1, p. 1 .

BRASIL. Decreto 9.311/2018 de 15 de marzo 2018. de Regularição Fundiária. Diário Oficial da União, 16 de marzo de 2018, seção l, p. 1.

BUAINAIN, A.M. et al. Sete Teses sobre o mundo rural brasileiro. Revista de Politica Agrícola, 2013, vol. 22, núm. 2, p. 105-121.

CASADO, L. STF mantém anistia a desmatadores no Código Florestal. <https://wwwl. folha.uol.com.br/ambiente/2018/02/stf-mantem-anistia-a-desmatadores-nocodigo-florestal.shtml> [18-02-2018].

CEPEA. Centro de Estudos Avançados em Economia Aplicada. PIB do Agronegócio: dados de 1996 a 2018. <https://www.cepea.esalq.usp.br/br/pib-do-agronegociobrasileiro.aspx $>$ [29-06-2018].

CONAB. Companhia Nacional de Abastecimento. Acompanhamento da safra brasileira, 2017, vol. 04, núm. 12. 124 p. 
COCA, E.L.F. Impactos do Programa de Aquisição de Alimentos nas unidades de produção camponesas do assentamento 8 de Junho em Laranjeiras do Sul - PR. Ideas, 2015, vol. 9, núm.1, p. 27-56.

DELGADO, G.C. Especialização primária como limite ao desenvolvimento. Desenvolvimento em Debate, 2010, vol. 1, núm.2, p. 111-125.

FAO. Superação da fome e da pobreza rural: iniciativas brasileiras. Brasil: FAO, 2016.

FNDE. Fundo Nacional de Desenvolvimento da Educação. Programa de Alimentação Escolar.<http://www.fnde.gov.br/programas/alimentacao-escolar/ alimentacao-escolar-consultas/alimentacao-escolar-dados-f\%C3\%ADsicos-efinanceiros-do-pnae?tmpl=component\&print=l> [25-1 1-2017].

FPA. Frente Parlamentar da Agropecuária. Pauta positiva biênio 2016-2017, p. 1-7. $<$ https://www.socioambiental.org/sites/blog.socioambiental.org/files/blog/ pdfs/pauta_bancada_ruralista.pdf>. [03-05-2016].

HIDALGO F.; HOUTART, F.; LIZÁRRAGA, P.A. Agriculturas campesinas en Latinoamérica: propuestas y desafíos. Quito: IAEN, 2014.

HOLT GIMÉNEZ, E. Campesino a campesino: voces de latinoamérica. Managua: SIMAS, 2008.

GRAS, C. y HERNÁNDEZ, V. Modelos de desarrollo e innovación tecnológica: una revolución conservadora. Mundo Agrario, 2016, vol. 17, núm. 36, p. 1-27, e028.

IBGE. Instituto Brasileiro de Geografia e Estatística. Sistema IBGE de Recuperação Automática: Censo Agropecuário 2006. Rio de Janeiro: IBGE, 2017. <http:// sidra.ibge.gov.br> [03-10-2017].

INCRA. Instituto Brasileiro de Colonização e Reforma Agrária. Sistema Nacional de Cadastro Rural: estatísticas cadastrais situação jurídica em 2014. Brasília: Incra, 2014.

JARA, C.E.; RODRÍGUEZ SPERAT, R.; RINCÓN MANRIQUE, L. F. La agricultura familiar en el desarrollo rural: continuidades y rupturas del paradigma neoliberal en Argentina y Colombia. NERA, 2014, vol. 17, núm. 24, p. 86-106.

LUTZENBERGER, J.A. O absurdo da agricultura. Estudos Avançados, 2001, vol. 15, núm. 43, p. 61-74.

MARÉS, C.F. A função social da terra. Porto Alegre: Safe, 2003.

MARTINS, J.S. O poder do atraso. São Paulo: Hucitec, 1994.

MARX, K. O capital: Libro 3 Volume 6. Rio de Janeiro: Civilização Brasileira, 1985.

MAZOYER, M. y ROUDART, L. História das agriculturas no mundo: do neolítico à crise contemporânea. São Paulo: UNESP, 2010.

MITIDIERO JUNIOR, M.A.; BARBOSA, H.J.N.; SÁ, T.H. Quem produz comida para os brasileiros? Pegada, 2018, vol. 18, núm. 3, p. 7-77.

NUNES, R. Avaliação do Impacto dos Programas PAA e PNAE na Renda da Agricultura Familiar em Municípios do Norte Pioneiro. Relatório Projeto CNPq Segurança alimentar e estudo sócio econômico nos projetos PNAE e PAA no Território da Cidadania Integração Norte Pioneiro do Paraná. Pirassununga, 2015, 9 p. 
OLIVEIRA, A.U. Barbárie e Modernidade: as transformações no campo e o agronegócio no Brasil. Terra Livre, 2003, vol. 21, núm. 1, p. 113-156.

OLIVEIRA, A. U. A mundialização da agricultura brasileira. São Paulo: Iandé, 2016.

PORTO GONÇALVES, C.W. A globalização da natureza e a natureza da globalização. Rio de Janeiro: Civilização Brasileira, 2006.

POLANYI, K. A grande transformação: as origens da nossa época. Rio de Janeiro: Campus, 1980.

PUGLIESI, A.A. Opinião dos agricultores familiares sobre o fornecimento de alimentos orgânicos para o Programa Nacional de Alimentação Escolar do Paraná. Tesis de Maestría, Universidade Federal do Paraná. Curitiba: UFPR, 2015.

RAFFESTIN, C. Por uma Geografia do poder. São Paulo: Ática, 1993.

ROSSET, P. The multiple functions and benefits of small farm agriculture in the context of global trade negotiations. Development, 1999, vol. 43, núm. 2, p. 7782.

SANTOS, A. R. Os movimentos sociais do campo e a Reforma Agraria do Consenso. Mundo Agrario, 2017, vol. 18, núm. 38, p. 1-21, e58.

SOBREIRO FILHO, J. et al. O golpe na questão agrária brasileira: aspectos do avanço da segunda fase neoliberal no campo. Boletim Dataluta, 2018, n. 122, p. 1-29.

SOUZA, P.H.G.F. A desigualdade vista do topo: a concentração de renda entre os ricos no Brasil, 1926-2013. Tesis Doctoral, Universidade de Brasília. Brasília: UNB, 2016.

VAN DER PLOEG, J. Peasant-driven agricultural growth and food sovereignty. The Journal of Peasant Studies, 2013, Conference Paper núm. 8, p. 1-33.

VIEGAS, G.L et al. A evolução do Programa de Aquisição de Alimentos. Boletim Conab: artigo do mes. Brasília: Conab, 2017.

VILLAS BOAS, B. Pobreza extrema aumenta $11 \%$ e atinge 14,8 milhões de pessoas. Valor Econômico de 12 de abril de 2018. <https://www.valor.com. br/brasil/5446455/pobreza-extrema-aumenta-11-e-atinge-148-milhoes-depessoas> [13-03-2018].

(C) Copyright: Eliane Paulino, 2019

(c) Copyright: Scripta Nova, 2019.

Ficha bibliográfica:

PAULINO, Eliane. Expansión de la producción y estancamiento de los ingresos agrícolas en Brasil: latifundios y pasivos territoriales como herencia del período post-liberal. Scripta Nova. Revista Electrónica de Geografía y Ciencias Sociales. Barcelona: Universidad de Barcelona, 1 de diciembre de 2019, vol. XXIII, $n^{\circ}$ 627. [ISSN: 1138-9788] 